\title{
Selection of effective industry benchmarks for the development of mono-specialized regions
}

\author{
Irina Danilova ${ }^{1}$, Natalya Pravdina ${ }^{2, *}$ \\ ${ }^{1}$ South Ural State University (National Research University), Economic Theory, Regional Economics, \\ State and Municipal Government Department, 454080, 76, Lenin prospect, Chelyabinsk, Russia \\ ${ }^{2}$ South Ural State University (National Research University), Industry Economics and Project \\ Management Department, 454080, 76, Lenin prospect, Chelyabinsk, Russia
}

\begin{abstract}
The development of the industrial potential of the regions is an urgent task of state policy and requires the development of a set of measures that can take into account not only the structural characteristics of the regional economy, but also the efficiency of the industries. A coupled assessment of changes in concentration and efficiency will allow to get a more complete picture of the sectoral structure of the region's economy and to more accurately rank measures of state support. The purpose of the article is to substantiate the criteria and assess the unidirectionality (multidirectionality) of shifts in industry concentration and efficiency on the example of monospecialized regions of the metallurgical profile. In the work, the assessment of the localization and efficiency of manufacturing industries by regions was carried out, the positioning of the regions according to the corresponding indicators and their comparative studies were carried out, taking into account the growth rates of the regional economy. According to the results of the assessment, the regions showed a different nature of changes in the manufacturing industry. The Krasnoyarsk Territory has demonstrated a high degree of efficiency with a low localization of the industry, while the growth rates of the regional economy are relatively low, which may indicate the ongoing restructuring processes in the manufacturing industry in favor of more competitive industries. The Chelyabinsk Region showed the highest localization with low efficiency, with the exception of investment efficiency, which may indicate difficulties in transforming the region's sectoral structure. The focus of further research can be aimed at assessing detailed types of activities within the manufacturing industry in order to identify the factors of ongoing changes and develop point measures to support the relevant industries. Keywords: effective specialization of regions, regional development, localization of activities, sectoral efficiency, monospecialized regions, sectoral benchmarks.
\end{abstract}

* Corresponding author: pravdinanv@susu.ru 


\section{Introduction}

In accordance with the national development goals in Russia by 2024 , it is planned to create a high-performance export-oriented sector in the basic sectors of the economy, in the manufacturing industry based on modern technologies, innovations and digitalization ${ }^{1}$. To achieve the goal, the strategy of the Regional Industrial Policy is being revised, until 2035 it is planned to stimulate the activity of regions to increase their industrial potential, form a competitive manufacturing sector, create conditions for long-term economic growth ${ }^{2}$. The indicators of the draft Strategy assume an increase in the number of regions in which the index of the physical volume of the gross value added of manufacturing is planned to be not lower than the index of the physical volume of the gross regional product, which accordingly requires diagnosing the situation in the economy of the Russian Federation regions, a balanced approach and defining development priorities.

To increase the competitiveness of the economy, it is necessary to take into account, in addition to modern technological and innovative trends, the reduction of traditional territorial resources and the actualization of the problem of the efficiency of their use, the increased instability of open regions. Such a problem is a priority for monospecialized regions, the economy of which in the Russian Federation is focused either on the extractive industry, or on the production of manufacturing products, but with a low technological level. The orientation of the state policy in relation to the regions towards the development of the industry of high technological level actualizes the processes of transformation of the sectoral structure of the regions, the optimization and selection of promising specializations, the identification of new management tools and support for the development of the territorial economy.

Structural changes and the formation of stable strategic specializations of the Russian Federation regions are primarily due to the existing production base, which determines the monospecialized or diversified nature of the economy, and, therefore, the concentration of efforts of the regions can be aimed at increasing of the sectoral efficiency. For monospecialized regions, the problem lies in the choice of a strategy to stimulate the reduction or strengthening of the profile industry, which primarily predetermines the diagnosis of changes in the performance indicators of industry activities and trends in the development of the industry as a whole. In accordance with the author's hypothesis, multidirectional shifts between localization and industry efficiency are not excluded. The purpose of this publication is to substantiate the monitoring criteria, according to which it is possible to identify the presence or absence of complementarity between changes in the parameters of industry concentration and efficiency using the example of the dynamics of the manufacturing industry in the regions of Russia with a metallurgical profile.

\section{Research methodology}

New spatial and strategic approaches to the analysis of regional economic systems and changes in the structure of the economy involve the study of factors and, first of all, the sufficiency of resource provision for development in terms of localization of employed, fixed assets [1-4], concentration processes, cooperation and the scale of regional industrial production [5-6], the growth rate of gross value added, the rate of structural shifts, in the commodity filling of exports and the level of its manufacturability, as the most significant indicator of the competitiveness of the

\footnotetext{
${ }^{1} \mathrm{http}: / /$ www.kremlin.ru/acts/bank/43027

$2 \mathrm{https} / /$ nangs.org/docs/minpromtorg-rossii-strategiya-regionalnoj-promyshlennoj-politiki-rossijskojfederatsii-do-2024-goda-i-na-period-do-2035-goda-proekt-ot-19-05-2021-g-docx
} 
economy [7-9] and others. It should be noted that the analysis of the susceptibility of the regional economy to crises and, as a consequence, the cyclical changes in the level of concentration / diversification in the sector of core activities, due to both exogenous and endogenous causes, including a change in scientific and technological platforms ${ }^{3}$, does not go unnoticed by researchers [10-13].

In a number of topical research areas, we consider it essential to deepen the understanding of the effectiveness of regional specializations as changes in the level of localization of basic activities. Typically, the reasons for shifts in the structure of the economy are considered from the perspective of macro- and meso-level processes (natural-geographical, infrastructural, etc.), while the actual dynamics of the results of sectoral use of resources remains the area of microeconomic analysis. We believe that the issue of identifying effective specializations of regions and connecting the assessment of the sectoral activities efficiency for building leadership strategies in key sectors of the economy, synchronizing and activating priorities, and developing mechanisms to stimulate regional development is relevant.

Mono-industry regions of the metallurgical profile in the Russian Federation are currently at different stages of evolution of the basic industries of specialization. Assessment of the current status and comparative studies of regions of the same type, close from the point of view of the sectoral nature of influencing factors, using the specified toolkit [14], will make it possible to concretize promising changes in the sectoral structure.

The object of this study - the regions characterized by mono-specialization in the manufacturing sector and profiling in metallurgical production: Lipetsk region (the share of manufacturing in GRP 44.7\% in 2018), Vologda region (42.4\%), Chelyabinsk region (36\%) and the Krasnoyarsk Territory (31.8\%), the share of metallurgy in the manufacturing industry ranges from 60 to $75 \%$.

To substantiate the hypothesis, we used comparative and coefficient analysis; the calculations included three stages.

Stage I. Assessment of private indicators of the level of localization and parameters of the efficiency of the manufacturing industry in monospecialized regions. Localization coefficients were calculated for 2010 and 2019; each efficiency indicator is defined as the arithmetic mean over a 10-year period (2010-2019); for comparability of results, all values are normalized. Averaging data on the efficiency indicator, in the opinion of the authors, makes it possible to neutralize changes in economic parameters associated with the crisis situation in 2013-2014, sanctions and anti-sanctions.

Stage II. For the purposes of comparative studies and a systemic vision of the results obtained, the positioning of the regions was carried out; for visualization, three coordinate systems were built in two directions of analysis. First, in the context of attention to the values of the localization coefficients, information on the concentration of employees, output and enterprises of the same industry makes it possible to compare regions and obtain analytical conclusions about the specifics of trends in the manufacturing industry of regions focused on this type of activity. Secondly, the analysis of efficiency indicators is devided as characterizing the functioning of the industry activity (main activity) and the parameters of the development efficiency (investment activity) of the manufacturing industry, which made it possible to highlight the advantages of the regions and obtain information that, with constant monitoring, can be used to make managerial decisions on adjustments of the strategic priorities.

3 Guide to Research and Innovation Strategies for Smart Specialisations (RIS 3) http://s3platform.jrc.ec.europa.eu/documents/20182/84453/RIS3+Guide.pdf/fceb8c58-73a9-4863$\underline{8107-752 \mathrm{aef} 77 \mathrm{e} 7 \mathrm{~b} 4}$ 
Stage III. Comparative studies of monospecialized regions in the context of localization and efficiency were carried out with the expansion of the analysis and taking into account the average growth rate of the gross regional product, the average growth rate of gross value added in the manufacturing industry, indicators of gross value added per person employed in the manufacturing industry. Average growth rates were calculated as the geometric mean for the period 2010-2018. The coefficients used in the calculations are formalized in Table 1.

Table 1. Indicators of localization and efficiency of the manufacturing industry.

\begin{tabular}{|c|c|c|c|}
\hline \multicolumn{2}{|c|}{ Indicators of localization } & \multicolumn{2}{|c|}{ Indicators of efficiency } \\
\hline Components & Characteristic & Components & Characteristic \\
\hline \multirow{2}{*}{$\begin{array}{l}\text { Localization coefficient } \\
\text { based on industry scale } \\
\text { parameters (by the number } \\
\text { of enterprises and } \\
\text { organizations) }\end{array}$} & \multirow{2}{*}{$\mathrm{K}_{\mathrm{l}}^{\mathrm{o}}=\frac{\mathrm{O}_{\mathrm{i}, \mathrm{g}}}{\mathrm{O}_{\mathrm{g}}} / \frac{\mathrm{O}_{\mathrm{i}, \mathrm{R}}}{\mathrm{O}_{\mathrm{R}}}$} & $\begin{array}{l}\text { Return on } \\
\text { investment }\end{array}$ & $K_{i}^{r}=\frac{G_{V A} A_{i, g}}{I_{i, g}}$ \\
\hline & & $\begin{array}{l}\text { Renovation of } \\
\text { fixed assets }\end{array}$ & $\kappa_{\mathrm{FA}}=\frac{\mathrm{FA}_{\mathrm{i}, \mathrm{g}}^{\text {new }}}{\mathrm{FA}_{\mathrm{i}, \mathrm{g}}}$ \\
\hline \multirow{2}{*}{$\begin{array}{l}\text { Localization coefficient by } \\
\text { the average annual number } \\
\text { of people employed }\end{array}$} & \multirow{2}{*}{$\mathrm{K}_{\mathrm{l}}^{\mathrm{e}}=\frac{\mathrm{E}_{\mathrm{i}, \mathrm{g}}}{\mathrm{E}_{\mathrm{g}}} / \frac{\mathrm{E}_{\mathrm{i}, \mathrm{R}}}{\mathrm{E}_{\mathrm{R}}}$} & $\begin{array}{l}\text { Investment per } \\
\text { employee }\end{array}$ & $K^{i}=\frac{I_{i, g}}{E_{i, g}}$ \\
\hline & & $\begin{array}{l}\text { Profitability of } \\
\text { sales }\end{array}$ & $\mathrm{K}_{\mathrm{s}}^{\mathrm{r}}$ \\
\hline \multirow[t]{2}{*}{$\begin{array}{l}\text { Localization coefficient by } \\
\text { the shipped goods }\end{array}$} & \multirow{2}{*}{$\mathrm{K}_{\mathrm{l}}^{\mathrm{g}}=\frac{\mathrm{G}_{\mathrm{i}, \mathrm{g}}}{\mathrm{G}_{\mathrm{g}}} / \frac{\mathrm{G}_{\mathrm{i}, \mathrm{R}}}{\mathrm{G}_{\mathrm{R}}}$} & Return on assets & $K_{A}^{r}$ \\
\hline & & Productivity & $K^{p}=\frac{G_{i, g}}{E_{i, g}}$ \\
\hline
\end{tabular}

where $\mathrm{i}$ - sector in the region $\mathrm{g}$ or in Russia R; $\mathrm{O}$ - number of organizations; $\mathrm{E}$ - the average annual number of people employed; G - shipped goods; GVA - gross value added; I - investments; $\mathrm{FA}^{\text {new }}$ - fixed assets put into operation; FA - fixed assets.

The use of coefficient analysis, visualization of the relationship between the obtained values and analytical techniques of comparative studies were a feature of the applied methodology of this article.

\section{Research results}

Approbation of the proposed methodology was carried out according to the official statistical data presented in the collections "Regions of Russia" for 2010-2019. The quantitative values of regional specialization are represented by localization indicators (Table 2).

Table 2. Indicators of localization of manufacturing industries, 2019*.

\begin{tabular}{|c|c|c|c|c|c|c|}
\hline \multirow{2}{*}{ Regions } & \multicolumn{2}{|c|}{$\mathrm{K}_{\mathrm{l}}^{\mathrm{e}}$} & \multicolumn{2}{c|}{$\mathrm{K}_{\mathrm{l}}^{\mathrm{o}}$} & \multicolumn{2}{c|}{$\mathrm{K}_{\mathrm{l}}^{\mathrm{g}}$} \\
\cline { 2 - 7 } & 2010 & 2019 & 2010 & 2019 & 2010 & 2019 \\
\hline Lipetsk region & 1,21 & 1,27 & 1,05 & 1,14 & 1,42 & 1,44 \\
\hline Vologda region & 1,40 & 1,41 & 0,96 & 0,99 & 1,41 & 1,43 \\
\hline Chelyabinsk region & 1,54 & 1,59 & 1,17 & 1,34 & 1,37 & 1,31 \\
\hline $\begin{array}{c}\text { Krasnoyarsk } \\
\text { Territory }\end{array}$ & 0,97 & 0,99 & 1,03 & 0,93 & 0,98 & 0,94 \\
\hline
\end{tabular}

* The maximum value is highlighted in dark gray, the minimum in gray.

In general, it should be noted that the concentration of the manufacturing industry has increased in all regions, with the exception of the Krasnoyarsk Territory. Among the studied regions, the highest values for two of the three localization indicators were noted in the 
Chelyabinsk region, the lowest - in the Krasnoyarsk Territory, the values of which are close to the national average. Thus, the Krasnoyarsk Territory of all similar regions is distinguished by the lowest concentration of the manufacturing industry and a tendency towards its weakening.

As for the Chelyabinsk region, it should be noted the high localization of the employed and the number of manufacturing enterprises with a relatively low localization of shipped products, while there is a tendency for its even greater reduction. The possibility of such a case is due to differences in the structure and share ratio of types of activity in the group of manufacturing industries, but questions about the reasons for the lower output of the manufacturing sector in the region with a high concentration of employees remain.

Lipetsk and Vologda regions in comparison with Chelyabinsk have the best localization rates by the shipped goods.

The positioning of regions in terms of localization indicators is shown in Figure 1, where the localization coefficients by the shipped goods and the number of enterprises are located along the axes, and the size of the circles corresponds to the value of the localization coefficient by the number of people employed in the manufacturing industry.

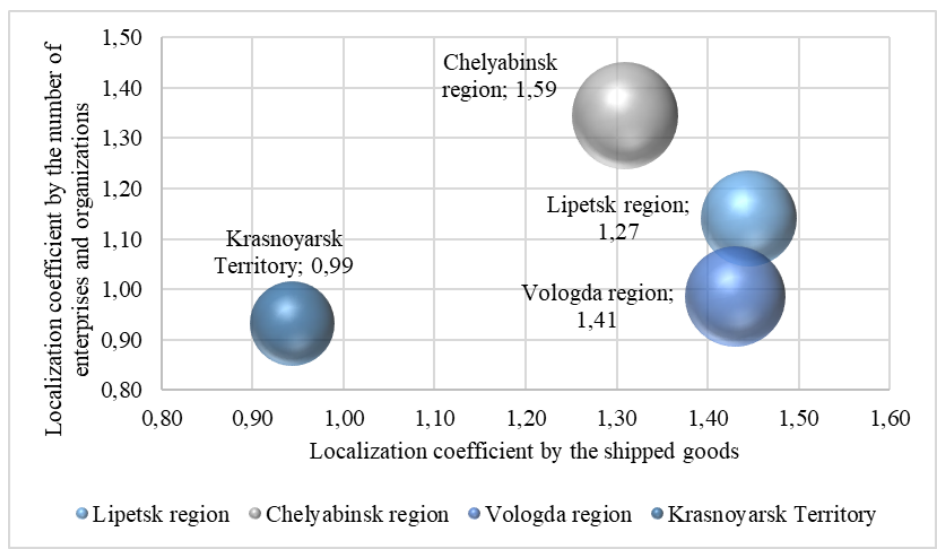

Fig. 1. Localization of manufacturing industries by region.

As can be seen in Figure 1, the Chelyabinsk region, accumulating employed and processing enterprises, lags behind the Lipetsk and Vologda regions in terms of the localization of shipment, in other words, attracting more resources, it ships fewer products, which is confirmed by further calculations of sectoral efficiency and productivity. In this regard, the indicators for the Krasnoyarsk Territory are more even, practically approaching the average Russian indicators.

The strategy for increasing labor productivity determines the need to monitor concentration indicators in the context of sub-sectors, since within the framework of the manufacturing industry changes in strategic priorities and leaders due to innovative technologies are not excluded.

Evaluation of the efficiency of manufacturing industries was carried out in two directions: 1) indicators of operational efficiency (efficiency of core activities: return on assets, profitability of sales and productivity as average annual output per employee in the manufacturing industry); 2) indicators of development efficiency (efficiency of investment activity: return on investment, renewal of fixed assets and the amount of investment per person employed in the manufacturing industry). The calculation results are presented in Table 3. 
Table 3. Indicators of manufacturing industries efficiency*.

\begin{tabular}{|c|c|c|c|c|c|c|}
\hline \multirow[t]{2}{*}{ Region } & \multicolumn{3}{|c|}{ Operational efficiency } & \multicolumn{3}{|c|}{ Development efficiency } \\
\hline & 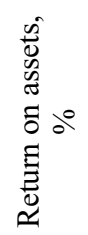 & 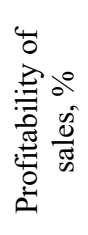 & 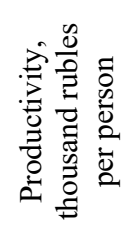 & 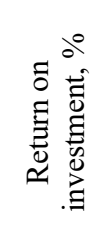 & 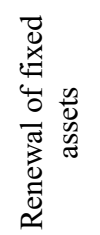 & 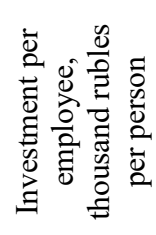 \\
\hline Lipetsk region & 7,82 & 12,01 & 4762,18 & 531,48 & 0,107 & 288,55 \\
\hline Vologda region & 8,61 & 15,33 & 4088,90 & 527,49 & 0,108 & 268,22 \\
\hline Chelyabinsk region & 4,83 & 11,33 & 2760,64 & 610,61 & 0,094 & 147,51 \\
\hline Krasnoyarsk Territory & 12,73 & 55,49 & 4237,16 & 587,97 & 0,104 & 391,15 \\
\hline
\end{tabular}

* The maximum value is highlighted in dark gray, the minimum in gray.

It should be noted that the lowest values in almost all efficiency indicators are in the Chelyabinsk region, despite the highest localization of the manufacturing industry.

For analytical purposes, information on the Russian Federation as a whole is presented (Table 4).

Table 4. Indicators of efficiency of the manufacturing industry in the Russian Federation.

\begin{tabular}{|c|c|c|c|}
\hline Indicators & 2010 & 2019 & $\begin{array}{c}\text { Mean 2010- } \\
2019\end{array}$ \\
\hline \multicolumn{4}{|c|}{ Operational efficiency } \\
\hline Return on assets, $\%$ & 8,20 & 6,90 & 5,92 \\
\hline Profitability of sales, $\%$ & 14,80 & 11,50 & 11,38 \\
\hline Productivity, thousand rubles per person & 1776,97 & 4761,36 & 3056,39 \\
\hline \multicolumn{4}{|c|}{ Development efficiency } \\
\hline Return on investment, $\%$ & 510,00 & 691,00 & 551,00 \\
\hline Renewal of fixed assets & 0,11 & 0,10 & 0,11 \\
\hline Investment per employee, thousand rubles per person & 126,08 & 241,73 & 186,96 \\
\hline
\end{tabular}

* Indicators with positive dynamics are highlighted in dark gray.

General trends in the manufacturing industry over a 10 -year period, concretizing the industry background: an increase in nominal per capita indicators, while from qualitative indicators, growth is observed only in return on investment, as an indicator of development efficiency, with a decrease in the parameters of renewal of fixed assets.

The positioning of the regions and the Russian Federation as a whole in terms of efficiency indicators is shown in Figures 2 and 3. In Fig. 2, along the axes are the profitability of assets and sales, the size of the circles corresponds to production, that is, shipment per person employed in the manufacturing industry. In figure 3 , the axes are the return on investment and the renewal of fixed assets, the size of the circles corresponds to investment per employee.

Note that high efficiency values both in comparison with similar regions and in comparison with the average Russian level allow us to speak about the leadership positions of the Krasnoyarsk Territory. The region appears to be transforming manufacturing towards more efficient activities. 


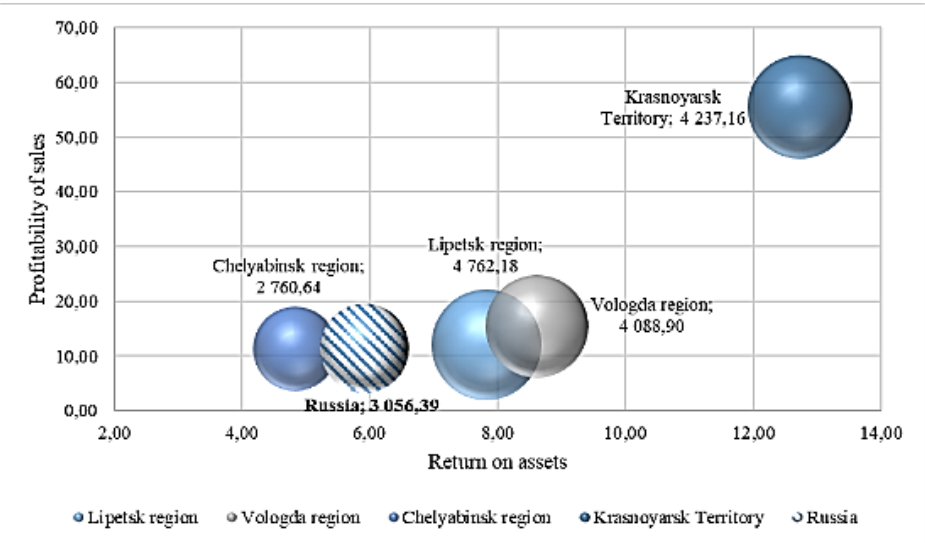

Fig. 2. Operational efficiency.

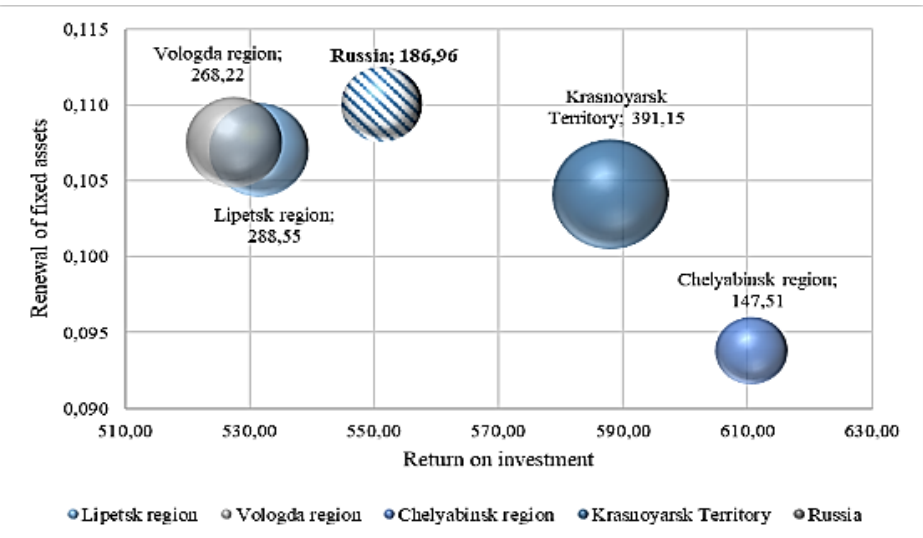

Fig. 3. Development efficiency.

The Chelyabinsk Region demonstrates the lowest efficiency of the manufacturing industry with high localization, lagging not only behind similar regions, but also behind the average Russian level, which, despite the relatively high return on investment, may be caused by difficulties in restructuring the economy.

It should be noted that with the average annual number of people employed in manufacturing in 2019 in the Krasnoyarsk Territory 194.3 thousand people, and in the Chelyabinsk region 392.6 thousand people, and low localization of the industry, the Krasnoyarsk Territory invests in the development of the manufacturing industry comparable to the Chelyabinsk region, maintaining a high level of renewal of fixed assets and investment efficiency.

Comparative studies of regions, taking into account the performance indicators of the economy as a whole (Table 5), testifies to the lagging behind of the Krasnoyarsk Territory in terms of the growth rate of GRP and GVA in the manufacturing industry, while the Chelyabinsk Region takes the penultimate place in terms of the indicators. At the same time, the highest specific value of GVA in the Krasnoyarsk Territory should be noted, which once again testifies to the high level of efficiency of the manufacturing industry in the region. In the region, the sectoral structure is being transformed by shrinking the manufacturing industry, changing the range of products in favor of more efficient types of activity, which at this stage leads to a slowdown in the pace of development of the regional economy. 
Table 5. Average growth rates of GRP and GVA in the manufacturing industry*.

\begin{tabular}{|c|c|c|c|}
\hline Region & $\begin{array}{c}\text { Average growth } \\
\text { rates of GRP }\end{array}$ & $\begin{array}{c}\text { Average growth rates } \\
\text { of GVA }\end{array}$ & $\begin{array}{c}\text { Average value of GVA in the } \\
\text { manufacturing industry per } \\
\text { one employed, thousand } \\
\text { rubles per person }\end{array}$ \\
\hline Lipetsk region & 102,32 & 112,43 & 1453,84 \\
\hline Vologda region & 102,74 & 111,97 & 1289,14 \\
\hline $\begin{array}{c}\text { Chelyabinsk } \\
\text { region }\end{array}$ & 102,23 & 110,64 & 887,52 \\
\hline $\begin{array}{c}\text { Krasnoyarsk } \\
\text { Territory }\end{array}$ & 101,99 & 108,99 & 2339,52 \\
\hline
\end{tabular}

* The maximum value is highlighted in dark gray, the minimum in gray.

The Vologda and Lipetsk regions are comparable in all the estimated indicators, but with a similar population size, the greater localization of those employed in the industry in the Volgograd region is associated with high parameters of the efficiency of sectoral production, both in the context of functioning and in the context of development.

\section{Results discussion}

The results obtained allow us to see the gaps between the regions for the aggregated group of manufacturing industries and to specify the choice of effective industry benchmarks for the development of monospecialized regions. Thus, for the Krasnoyarsk Territory, a policy aimed at further supporting effective types of economic activity is advisable, which in the future will accelerate the pace of economic growth. The case of the Chelyabinsk region sets the task of conducting a detailed study of the manufacturing industries from the standpoint of their efficiency in order to identify the leaders and outsiders of industry development.

The study forces us to focus on the optimization of regional processes and the specification of government instruments on the creation of conditions to stimulate efficient industrial production: the creation of cluster chains, the renewal of fixed assets, participation in state programs for the development of an innovative economy in the regions.

The traditional discussion on priority growth factors in the situation of analysis of the same industry predetermines the need to focus on efficiency and the list of problems, especially since the Ministry of Industry and Trade of the Russian Federation offers a wide range of measures to reduce the inefficiency of industry activities. The lack of attention of the regions and the limitedness of official statistical data to aggregate information limits the potential for determining and monitoring the development of the economy, both in terms of identifying reserves and in strengthening the instrumental apparatus for neutralizing them.

The focus of further research can be aimed at assessing detailed types of economic activity within the manufacturing industry in order to determine the factors of structural transformation of the economy of monospecialized regions.

\section{Conclusion}

A comprehensive assessment of the manufacturing industry, taking into account not only localization, but also the efficiency of the functioning and development of the industry, made it possible to see differences in the trajectories of sectoral development of monospecialized regions. We believe that sectoral support measures, both from the federal center and from regional authorities, provided on a competitive basis or on the basis of co-financing, should take into account production efficiency indicators. We believe that in the roadmap for the 
implementation of the development strategy for the basic sectors of the economy, in order to rank government support, it is necessary to monitor sectoral efficiency.

\section{Acknowledgments}

The research was funded by RFBR and Chelyabinsk Region, project number 20-410-740004.

\section{References}

1. Md. S. Rana, F. Hossain, IOSR-JHSS, 12, 72-77 (2013)

2. V. Sipiliva, 3rd Economics \& Finance Conference (2015)

3. C.I. Nesterova, L.N. Balikova, J. ISSN: 2071-9558, 31-39 (2017)

4. C.I. Yakovleva, J. Reg. ekon. upr. (2019)

5. Y.P. Silin, E.G. Animiza and N.V. Novikova, J. Upravlenets, 2-11 (2017)

6. A.I. Ziryanov, J. ISSN: 2587-5566, 23-31 (2014)

7. R. Boschma, M. Asier, N. Mikel, J. ISSN:1944-8287, 89, 29-51 (2013)

8. A.S. Kaukin, L. Freiknman, J. ISSN: 1994-5124, 99-117 (2009)

9. A. Apokin, A. Gnidchenko and E. Sabelnikova, J. ISSN: 1994-5124, 44-71 (2017)

10. J. Imbs, R. Wacziarg, AER, 93, 63-86(2003)

11. O. Cadot, C. Carrère and V. Strauss-Kahn, ISSN: 0034-6535, 93 (2011)

12. S. Zemtsov, V. Barinova, A. Pankratov and E. Kutsenko, J. Foresight-Russia, 10, 34-52 (2016)

13. S.A. Beloglazova, J. ISSN 2222-9167, 8, 148-157 (2018)

14. I.V. Danilova, N.V. Pravdina, J. ISSN: 2413-1016, 15, 24-36 (2021) 